\title{
Gommunications.
}

\section{Note sur Sagra humeralis Jacoby [CoL. Phytophagd] et description de la femelle de cette espèce}

\section{par J. ACHARD.}

Je rapporte à Sagra humeralis Jacoby, décrit d'après un seul individu mâle provenant de Mouy Tsé (Tonkin), deux insectes ( $\sigma^{x}$ et $q$ ) récoltés à Tali (Haut-Yunnan). Ils diffèrent quelque peu de l’insecte décrit par JACOBY, notamment par leur couleur qui est d'un noir franc et non "purplish black », par la forte ponctuation de la tête, par la forme du prothorax qui est sensiblement aussi long que large et non " scarcely one half broader than long ", par la pubescence des fémurs postérieurs du $\sigma^{7}$ qui est clairsemée et non dense, enfin par la taille sensiblement plus petite.

Ces différences, purement individuelles sans doute, sont intéressantes à signaler pour fixer les limites entre lesquelles peut varier l'espèce.

D'autre part, il y a lieu de faire connaitre la femelle que JАсову n'a pas vue. J'en profiterai pour insister, dans la description suivante, sur un certain nombre de caractères importants dont il n'est pas question dans la description de JACOBY :

Brevis, lata, omnino aterrima, supra depolita, subtus nitidior, elytris subtilissime rugulosis, macula quadrangulare cupreo-rubro-fulgente notatis; femoribus posterioribus compressis, latissimis, tridentatis, subtus remotiusculisque pubescentibus (in $\sigma^{\top}$ ), glabris unidentatisque (in 9 ); tibiis posterioribus (in $\sigma^{\top}$ ) medio dente externo incurvato armatis.

$\sigma^{x}$. Court, large, entièrement d'un noir profond, mat sur les élytres et le pronotum, plus brillant en dessous; calus huméral marqué d'une grande tache quadrangulaire rouge cuivreux éclatant.

Tête couverte de points enfoncés subconfluents; sillons frontaux postérieurs à peine indiqués, lisses et brillants au fond, dépassant le bord supérieur des yeux; sommet de l'épistome coupé droit et liseré de fauve; labre roux ferrugineux. Antennes robustes, atteignant le milieu des élytres, entièrement ponctuées; $1^{\mathrm{er}}$ article gros, renflé, les $2^{\mathrm{e}}, 3^{\mathrm{e}}, 4^{\mathrm{e}}$ et $\mathrm{\jmath}^{\mathrm{e}}$ renflés au sommet, les suivants plus allongés, le $11^{\mathrm{e}}$ cylindrique, atténué aux deux extrémités. 
Prothorax presque carré; bord apical légèrement convexe; angles antérieurs saillants; couvert en dessus de gros points ronds irrégulièrement espacés, plus serrés dans la région de l'angle antérieur; une légère fossette vaguement indiquée, a quelque distance de la base, en face de l'écusson.

Élytres peu allongés, se rétrécissant légèrement et progressivement a partir de leur quart postérieur, munis à leur base d'une carène étroite, ondulée, contiguë à l'écusson et atteignant le calus huméral; celui-ci fortement saillant; région scutellaire à peine sensiblement relevée et non limitée en arrière par une dépression. Élytres couvertes d'une rugosité extrèmement fine, plus apparente au sommet et au milieu de laquelle se distinguent, surtout sur les còtés, de très fines strioles transversales; ponctuation disposée en lignes régulières de points très fins, bien visibles jusqu'au quart postérieur où elles se perdent peu à peu dans la fine rugosité du fond.

Écusson noir brillant, faisant légèrement saillie au-dessus du niveau des élytres, déprimé longitudinalement en son milieu.

Saillie prosternale un peu élevée, très comprimée entre les hanches, s'abaissant obliquement et se terminant en spatule à son sommet. Saillie mésosternale oblique, relevée sur ses bords et creusée d'un canalicule longitudinal, élevée en un tubercule dépassant insensiblement la saillie des hanches et légèrement dirigé en arrière.

Fémurs des deux paires antérieures renflés, comprimés, finement pointillés, surtout au sommet. Fémurs postérieurs dépassant à peine le sommet des élytres, assez fortement incurvés et comprimés, grêles à leur base et très fortement dilatés à partir du quart de leur longueur, carénés en dessus et en dessous, la carène supérieure arrondie, l'inférieure tranchante et portant trois petites dents espacées; pubescence sexuelle clairsemée, d'une couleur gris sale, disposée en bande et localisée dans la concavité inférieure du fémur. Tibias antérieurs presque droits, canaliculés extérieurement dans presque toute leur longueur. Tibias intermédiaires fortement courbés. Tibias postérieurs assez grêles, flexueux, portant en leur milieu, extérieurement, une forte et longue dent, incurvée régulièrement et s'écartant fortement de l'axe de la jambe.

Premier segment abdominal glabre, marqué de points très espacés et assez profonds, à peine un peu moins convexe que celui de la femelle. Deuxième, troisième et quatrième segments bordés de roux ferrugineux au sommet; le cinquième densément ponctué au sommet.

q. Plus petite que le mâle, auquel elle ressemble en tous points, sauf en ce qui concerne les pattes postérieures. Les fémurs de celles-ci 
n'atteignent pas tout à fait le sommet des élytres et ne portent en dessous qu'une petite dent tuberculiforme, située non loin du sommet; les tibias sont grêles, régulièrement incurvés et privés de la grande dent médiane.

Longueur: ơ 10 mill.; $q, 8$ mill. - Largeur aux épaules : $\Im^{x}$, 4 mill. $1 / 2$; \& 3 mill. $1 / 2$.

La connaissance de la $q$ de $S$. humeralis Jac. confirme la parenté étroite de cette espèce avec $S$. Peteli Lac., de Java, près duquel elle doit prendre place.

\section{Les Silis Latr. du Tonkin et de Cochinchine}

[Col. Malacodermata]

par Maurice PIC.

Une demi-douzaine seulement d'espèces rentrant dans le genre Silis Latr. sont connues du Tonkin ou de la Cochinchine; les unes offrent une coloration élytrale foncée : $S$. carinaticeps Pic, Donckieri Pic, du Tonkin $\left({ }^{1}\right)$; une seule a les élytres bicolores, c'est-à-dire testacés à bordure noire : atrocincta Pic; enfin, les autres, dont je vais m'occuper ici, présentent une coloration élytrale testacée : $S$. robusticornis Pic, grandiceps Pic $\left(^{2}\right)$, déjà décrites, puis $S$. Lajoyei, n. sp.

Après la description de cette dernière espèce, je donnerai un tableau dichotomique qui aidera a la distinguer de ses deux voisines.

Silis Lajoyei, n. sp., @. - Modice elongata et satis lata, nitida, griseo pubescens, testacea, elytris pallidioribus, oculis, antennis, geniculis, tibiis tarsisque nigris.

Modérément allongé et assez large', brillant, revètu d'une pubes-

(1) Je possède une $3^{\ominus}$ espèce inédite, du Tonkin, que je nomme Silis tonkinea, n. sp.; celle-ci est assez allongée; le prothorax est sinué et fortement entaillé sur les côtés; cet organe est testacé, les cuisses et la base des tibias sont également testacés, le devant de la tête est roux, et le reste du corps noir. Long. 5 mill.

(2) Cette espèce est originaire de Vinh-Long, en Cochinchine (et non WinkLang, comme il a été imprimé au moment de la description de l'espèce ( $L^{\prime} \dot{E}$ change, $\mathrm{N}^{\circ} 318$ [1911], p. 144). 


\section{$2 \mathrm{BHL}$ Biodiversity Heritage Library}

1913. "Note sur Sagra humeralis Jacoby et description de la femelle de cette espece." Bulletin de la Société entomologique de France 1913, 161-163. https://doi.org/10.5962/bhl.part.16279.

View This Item Online: https://www.biodiversitylibrary.org/item/36377

DOI: https://doi.org/10.5962/bhl.part.16279

Permalink: https://www.biodiversitylibrary.org/partpdf/16279

\section{Holding Institution}

Smithsonian Libraries

\section{Sponsored by}

Smithsonian

\section{Copyright \& Reuse}

Copyright Status: NOT_IN_COPYRIGHT

This document was created from content at the Biodiversity Heritage Library, the world's largest open access digital library for biodiversity literature and archives. Visit BHL at https://www.biodiversitylibrary.org. 